\title{
Effects of TMB-8, an intracellular calcium antagonist, and W-7, a calmodulin antagonist, on prostaglandin output from the guinea-pig uterus
}

\author{
N. L. Poyser \\ Department of Pharmacology, University of Edinburgh Medical School, 1 George Square, \\ Edinburgh EH8 9JZ, U.K.
}

\begin{abstract}
Summary. TMB-8, an intracellular $\mathrm{Ca}^{2+}$ antagonist, inhibited the A23187-induced increase in outputs of prostaglandin (PG) F-2 $\alpha$ and 6-keto-PGF-1 $\alpha$ from the guinea-pig uterus superfused in vitro. The high basal output of PGF-2 $\alpha$ from the Day-15 guinea-pig uterus was not inhibited by TMB-8, indicating that a maintained high intracellular free $\mathrm{Ca}^{2+}$ concentration is not necessary for maintaining this high output of PGF-2 $\alpha$. W-7, a calmodulin antagonist, had similar actions except that PGF- $2 \alpha$ output from the Day-15 uterus was reduced $20-30$ min after the W-7 treatment had stopped. Overall, these findings suggest that, in the guinea-pig, oestradiol acting on a progesterone-primed uterus causes a prolonged stimulation of endometrial phospholipase A-2 in the absence of a maintained high $\mathrm{Ca}^{2+}$ concentration, thus providing a continuous release of arachidonic acid for increased endometrial PGF- $2 \alpha$ synthesis during the last third of the oestrous cycle.
\end{abstract}

\section{Introduction}

There is much evidence that prostaglandin (PG) F-2 $\alpha$ is the uterine luteolytic hormone in nonprimate mammalian species, including the guinea-pig (see Horton \& Poyser, 1976; Poyser, 1981). The outputs of PGF-2 $\alpha$, PGE-2 and 6-keto-PGF-1 $\alpha$ from the guinea-pig uterus superfused in vitro increase 21.9-, 1.8- and 2.9-fold, respectively, between Days 7 and 15 of the oestrous cycle (Poyser \& Brydon, 1983). Oestradiol acting on a progesterone-primed uterus appears responsible for this relatively specific increase in PGF-2 $\alpha$ output (Poyser, 1983a). The stimulation of phospholipase A-2 (PLA-2, EC 3.1.1.4) by $\mathrm{Ca}^{2+}$ may be important in the process by which these steroid hormones 'switch on' PGF-2 $\alpha$ synthesis by and release from the guinea-pig endometrium after Day 11 of the cycle, since PLA-2 is a $\mathrm{Ca}^{2+}$-requiring enzyme (Downing \& Poyser, 1983). The high output of PGF- $2 \alpha$ from the Day-15 guinea-pig uterus superfused in vitro is maintained for at least $2 \cdot 5 \mathrm{~h}$ in the absence of extracellular $\mathrm{Ca}^{2+}$ (Poyser, 1984a), suggesting that $\mathrm{Ca}^{2+}$ of intracellular origin is involved in maintaining this high output of PGF-2 $\alpha$. Consequently, the effects of $8-(N, N-$ diethylamino) octyl-3,4,5-trimethoxybenzoate hydrochloride (TMB-8), an intracellular $\mathrm{Ca}^{2+}$ antagonist (Malagodi \& Chiou, 1974), on basal and A23187-stimulated PG output from the guinea-pig uterus superfused in vitro have been studied, and have been compared with the effects of $N$-(6-aminohexyl)-5-chloro-1-naphthalene-sulphonamide (W-7), a calmodulin antagonist (Hidaka et al., 1978). Trifluoperazine, another calmodulin antagonist, has previously been shown to inhibit the A23187-stimulated increase in uterine PG output without inhibiting basal PG output (Poyser, 1985).

\section{Materials and Methods}

Thirty virgin guinea-pigs weighing $650-900 \mathrm{~g}$ were examined daily and a vaginal smear was taken 
when the vagina was perforate. The first day of the oestrous cycle was taken as the day preceding the post-ovulatory influx of leucocytes when cornification is at a maximum. The guinea-pigs were killed by stunning and incising the neck, on Day 7 or Day 15 of the cycle. A blood sample was collected with a heparinized $(20 \mathrm{U} / \mathrm{ml})$ syringe from the incised neck of each guinea-pig. The blood was centrifuged at $2500 \mathrm{~g}$, and the plasma was withdrawn and stored at $-20^{\circ} \mathrm{C}$ before being assayed for progesterone as described previously (Poyser \& Horton, 1975; Poyser, 1984b).

The two uterine horns in each guinea-pig were removed, weighed and 'opened' by cutting longitudinally. Each uterine horn was suspended in an organ bath and attached to an isotonic lever under a tension of $2 \mathrm{~g}$. Both uterine horns were superfused independently with Krebs' solution ( $4 \mathrm{ml} / \mathrm{min}$, for composition see Mitchell, Poyser \& Wilson, 1977) at $37^{\circ} \mathrm{C}$, pre-gassed with $5 \% \mathrm{CO}_{2}$, $95 \% \mathrm{O}_{2}$. After an initial settling period of $60 \mathrm{~min}$, samples of superfusate were collected for $10 \mathrm{~min}$ periods consecutively over the next 90 or $100 \mathrm{~min}$ (i.e. 9 or 10 samples/uterine horn). Additions of TMB-8 (100 or $150 \mu \mathrm{M}$; Aldrich Chemical Co. Ltd, Gillingham, Kent, U.K.), W-7 (100 or $150 \mu \mathrm{M})$ and A23187 ( $1 \mu \mathrm{g} / \mathrm{ml}$; Sigma Chemical Co. Ltd, Poole, Dorset, U.K.) were made to the Krebs' solution before being superfused over the tissues as indicated in the Text-figures ( 5 guinea-pigs/ experiment). After collection, PGs in each sample were extracted as described previously (Poyser, 1984b), and stored at $-20^{\circ} \mathrm{C}$ before being assayed. The recovery of PGs is greater than $80 \%$ (Poyser \& Scott, 1980; Swan \& Poyser, 1983), so the results have not been corrected for recovery. During the period of superfusate collection, the tone of the uterus was noted.

Details of radioimmunoassay. PGF-2 $\alpha$, PGE-2 and 6-keto-PGF-1 $\alpha$ were measured using antibodies raised in rabbits and tested in this laboratory (Dighe, Emslie, Henderson, Rutherford \& Simon, 1975; Poyser, 1980; Poyser \& Scott, 1980; Lytton \& Poyser, 1982). The only significant cross-reactivities were PGE-1 (66\%), PGA-2 (25.5\%) and PGB-2 (11.8\%) with the PGE-2 antiserum, and PGF-1 $\alpha(100 \%)$ with the PGF- $2 \alpha$ antiserum. Previous studies involving analysis by gas chromatography and mass spectrometry have shown that the guinea-pig uterus synthesizes very little PGF-1 $\alpha$ in comparison to PGF-2 $\alpha$, and that there is no detectable synthesis of PGE-1, PGB-2 and PGA-2 (Poyser, 1983b). It is therefore likely that the PGF-2 $\alpha$ and PGE-2 antibodies were measuring predominantly the prostaglandin to which they had been raised. The intra-assay coefficients of variation, calculated from the variation between the duplicate results obtained for each sample were 9.8\% (PGF-2 $\alpha$ ), 9.9 (PGE-2) and 10.9\% (6-keto-PGF-1 $\alpha$ ). The inter-assay coefficients of variation, calculated from the results of adding a known amount of the appropriate prostaglandin to each assay were $9 \cdot 2 \%$ (PGF-2 $\alpha$ ), 9.6\% (PGE-2) and $12 \cdot 8 \%$ (6-keto-PGF-1 $\alpha$ ). The limits of detection were $30 \mathrm{pg}$ (PGF-2 $\alpha$ ), $30 \mathrm{pg}$ (PGE-2) and $40 \mathrm{pg}$ (6-keto-PGF-1 $\alpha$ ).

Statistical tests. Changes in output of a particular PG with time were analysed by Duncan's multiple range test. Other comparisons were made using Student's $t$ test.

\section{Results}

\section{Basal uterine $P G$ output}

TMB-8 $(150 \mu \mathrm{M})$ had no inhibitory effect on the output of PGs from the Day-15 guinea-pig uterus. In fact, TMB- $8(150 \mu \mathrm{M})$ caused a small transient increase on the outputs of PGF- $2 \alpha$ $(P<0.05)$ and 6-keto-PGF-1 $\alpha$, and a more prolonged stimulation of PGE-2 output $(P<0.05$;

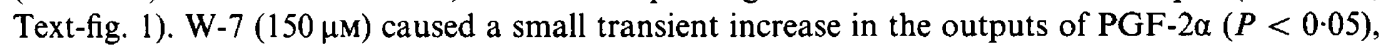
PGE-2 and 6-keto-PGF- $1 \alpha(P<0.05)$, and also had no inhibitory effect on PG output while being superfused over the Day-15 uterine tissue. However, PGF-2 $\alpha$ output was significantly reduced $(P<0.05)$ 20-30 min after the W-7 treatment had stopped (Text-fig. 1). Mean ( \pm s.e.m., $n=5)$ plasma concentrations $(\mathrm{ng} / \mathrm{ml})$ of progesterone were $0.20 \pm 0.05$ and $0.36 \pm 0.10$ in the groups subsequently treated with TMB-8 and W-7, respectively; the values were in the expected range (Poyser \& Horton, 1975). 


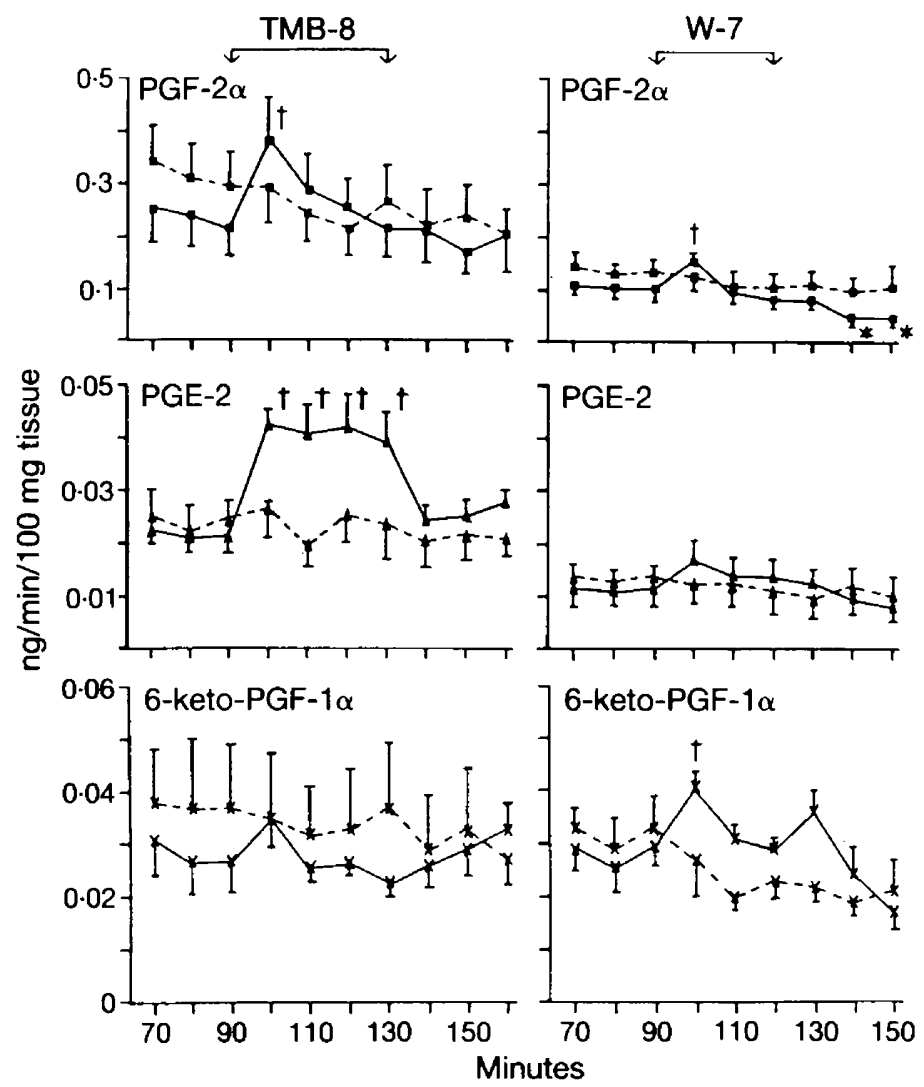

Text-fig. 1. Effect of TMB-8 $(150 \mu \mathrm{M})$ and W-7 (150 $\mu \mathrm{M})$ (solid lines) on mean ( \pm s.e.m., $n=5$ ) basal outputs of prostaglandin (PG) F-2 $\alpha$, PGE-2 and 6-keto-PGF-1 $\alpha$ from the Day-15 guinea-pig uterus superfused in vitro. For any one PG receiving any particular treatment: †significantly greater than values before treatment $(P<0.05)$ : *significantly lower than value before treatment $(P<0.05)$.

\section{A23187-stimulated uterine PG output}

A23187 stimulated the outputs of PGF-2 $\alpha(P<0.05)$, PGE-2 and 6-keto-PGF-1 $\alpha(P<0.05)$ from the Day-7 guinea-pig uterus. TMB-8 $(100 \mu \mathrm{M})$ and $\mathrm{W}-7(100 \mu \mathrm{M})$ partly $(40-60 \%)$ but significantly $(P<0.05)$ inhibited the stimulatory effect of A23187 on the outputs of PGF-2 $\alpha$ and 6-keto-PGF-1 $\alpha$. W-7 appeared to have no inhibitory effect on the increase in PGE-2 output, whereas any inhibitory effect on TMB- 8 was masked by the prolonged stimulation of PGE- 2 by TMB-8 (Text-figs 2a \& 2b). By 20 min after stopping the combined TMB-8 and A23187 treatment, a significant increase $(P<0.05)$ in 6-keto-PGF-1 $\alpha$ output occurred and the maximum output obtained was not significantly different from the maximum output obtaining during A23187 treatment alone (Text-fig. 2a). A similar phenomenon occurred following the cessation of combined W-7 and A23187 treatment, except that the maximum value obtained was significantly lower $(P<0.05)$ than with A23187 treatment alone $(P<0.05$; Text-fig. $2 \mathrm{~b})$.

TMB-8 $(150 \mu \mathrm{M})$ and W-7 $(150 \mu \mathrm{M})$ completely inhibited $(P<0.01)$ the stimulatory effect of A23187 on the outputs of PGF-2 $\alpha$ and 6-keto-PGF-1 $\alpha$ from the Day-15 guinea-pig uterus. W-7 $(150 \mu \mathrm{M})$ also prevented the stimulation of PGE-2 output by $\mathrm{A} 23187(P<0.05)$, but any inhibitory effect of TMB-8 on A23187-stimulated PGE-2 release was again masked due to the stimulation of PGE-2 output by TMB-8 (Text-figs 3a \& 3b). The output of 6-keto-PGF-1 $\alpha$ again increased after the cessation of combined treatment with A23187 and TMB-8 or W-7. 


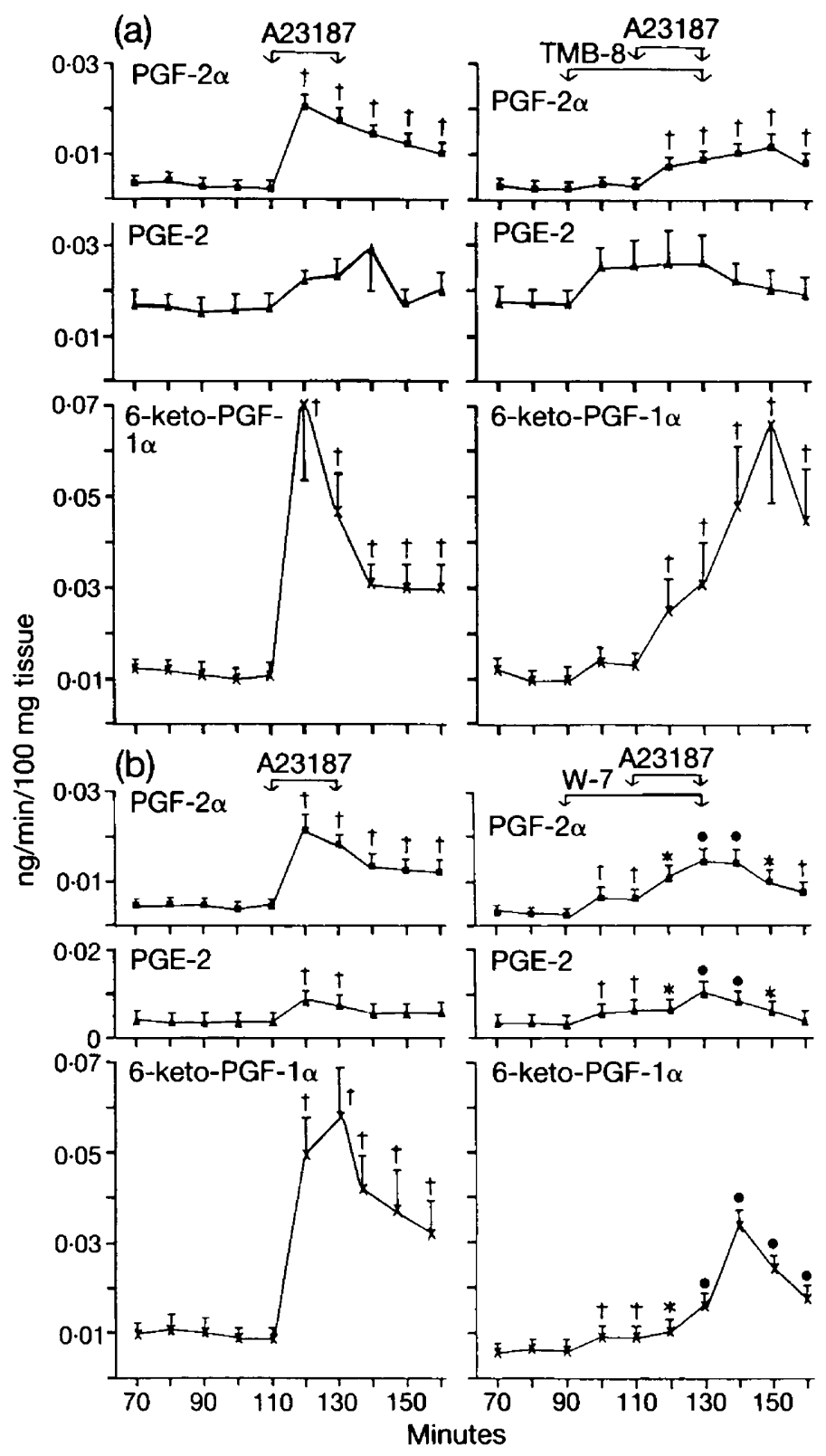

Text-fig. 2. Effect of (a) TMB-8 $(100 \mu \mathrm{M})$ and (b) W-7 $(100 \mu \mathrm{M})$ on mean ( \pm s.e.m., $n=5)$ A23187-stimulated outputs of prostaglandin (PG) F-2 $\alpha$, PGE-2 and 6-keto-PGF-1 $\alpha$ from the Day-7 guinea-pig uterus superfused in vitro. For any one $P G$ receiving any particular treatment on only the left-hand or right-hand side: $\dagger$ significantly greater than values before any treatment $(P<0.05)$; * significantly greater than values before any treatment but not with TMB-8 or W-7 treatment alone $(P<0.05)$; significantly greater than values before any treatment and with TMB-8 or W-7 treatment alone. 


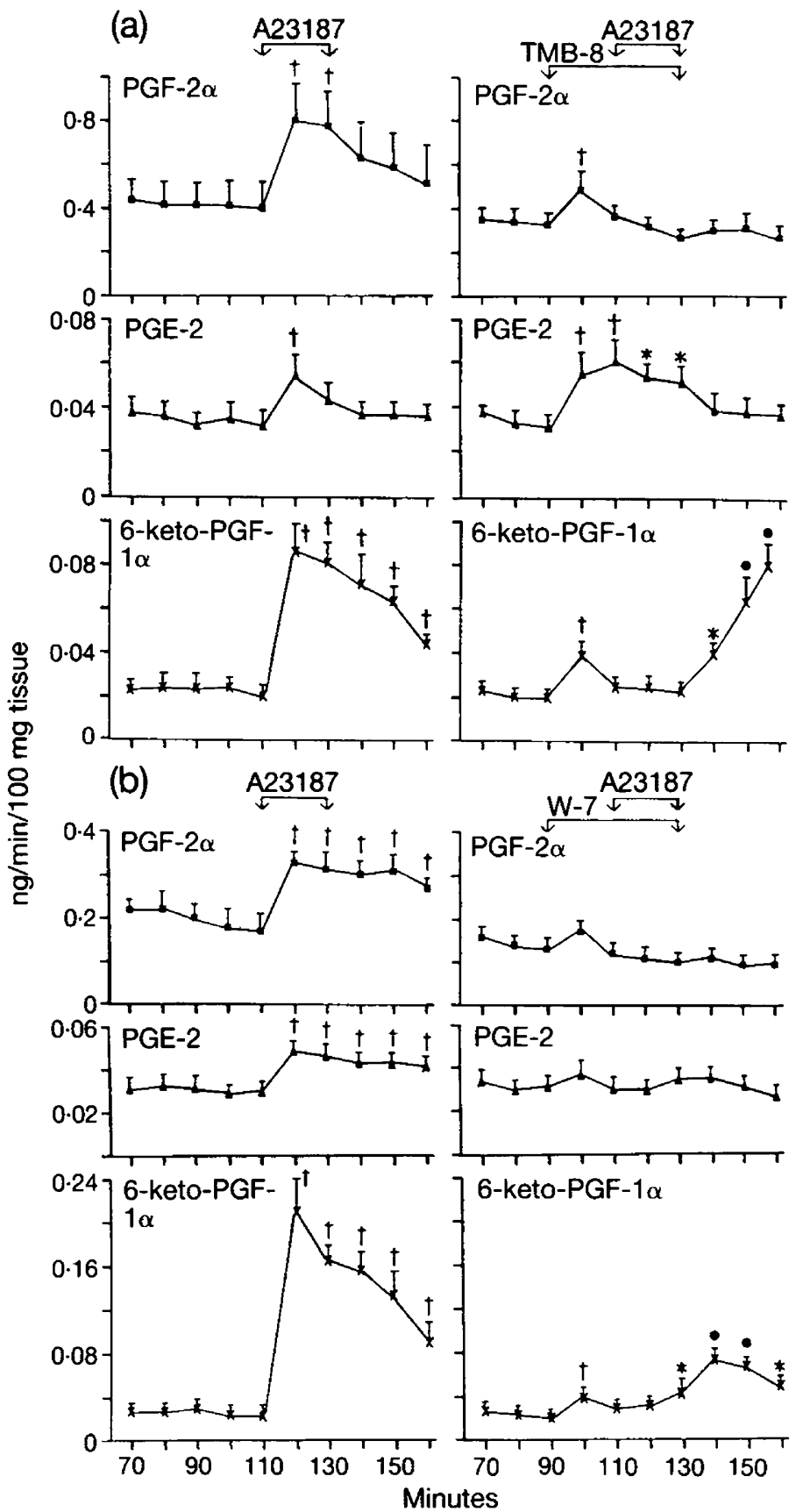

Text-fig. 3. Effect of (a) TMB-8 $(150 \mu \mathrm{M})$ and (b) W-7 $(150 \mu \mathrm{M})$ on mean ( \pm s.e.m., $n=5)$ A23187-stimulated outputs of prostaglandin (PG) F-2 $\alpha$, PGE-2 and 6-keto-PGF-1 $\alpha$ from the Day-15 guinea-pig uterus superfused in vitro. For any one PG receiving any particular treatment on only the left-hand or right-hand side: $\dagger$ significantly greater than values before any treatment $(P<0.05)$; ${ }^{*}$ significantly greater than values before any treatment but not with TMB-8 or W-7 treatment alone $(P<0.05)$; - significantly greater than values before any treatment and with treatment with TMB-8 or W-7 alone and in combination with A23187 $(P<0.05)$. 
Mean ( \pm s.e.m., $n=5$ ) plasma concentrations $(\mathrm{ng} / \mathrm{ml})$ of progesterone were $4 \cdot 14 \pm 0.66$ and

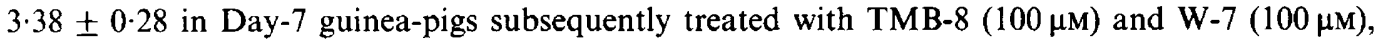
respectively, and were $0.17 \pm 0.02$ and $0.25 \pm 0.04$ in Day-15 guinea-pigs subsequently treated with TMB-8 $(150 \mu \mathrm{M})$ and $\mathrm{W}-7(150 \mu \mathrm{M})$, respectively. The values were in the expected range (Poyser \& Horton, 1975).

\section{Uterine tone}

All uterine horns showed occasional spontaneous contractions of short duration ( $<1 \mathrm{~min}$ ) which occurred at random during the period of superfusion. When A23187 was used alone, the uterus slowly contracted during the first minute and then remained fully contracted during the rest of the experiment, even when the A23187 was removed, although some Day-15 uterine horns showed short periods $(<1 \mathrm{~min})$ of partial relaxation.

When TMB-8 (100 or $150 \mu \mathrm{M})$ was superfused over the tissues, the uterus slowly contracted during the first minute, remained fully contracted during the second minute, and then fully relaxed during the next $3 \mathrm{~min}$ and remained relaxed. Spontaneous contractions were abolished. However, 10-12 min after stopping TMB-8 treatment, the tone of the uterus increased very slowly to reach approximately $80 \%$ of the maximum contraction by the end of the experiment. TMB- $8(150 \mu \mathrm{M})$ completely inhibited and TMB-8 $(100 \mu \mathrm{M})$ partly inhibited the increase in tone induced by A23187. After stopping the combined treatment, the tone of the uterus slowly increased.

$\mathrm{W}-7(100 \mu \mathrm{M})$ had no effect on the spontaneous activity of the uterus but did abolish the increase in tone induced by A23187, while W-7 $(150 \mu \mathrm{M})$ inhibited both the spontaneous activity and A23187-induced contraction. After stopping W-7 (100 or $150 \mu \mathrm{M})$ treatment, there was a gradual increase in tone $12-20 \mathrm{~min}$ later up to $50-80 \%$ of the maximum contraction, and this occurred irrespective of whether W-7 had been used alone or with A23187.

\section{Discussion}

The increase in PG output from the guinea-pig uterus superfused in vitro by A23187 is dependent upon the presence of extracellular $\mathrm{Ca}^{2+}$ (Poyser, 1984a). Presumably, the calcium ionophore causes an influx of $\mathrm{Ca}^{2+}$ into the uterine cells which in turn stimulates PLA-2 to release arachidonic acid from phospholipids (the major source of arachidonic acid in the guinea-pig uterus; Leaver \& Poyser, 1981) for PG synthesis. TMB-8 $(150 \mu \mathrm{M})$ completely abolished this stimulatory effect of A23187 on uterine output from the Day-15 guinea-pig uterus indicating that, at this concentration, TMB-8 is able to antagonize fully the effects of a rise in the intracellular free $\mathrm{Ca}^{2+}$ concentration in the uterus. However, the high basal output of PGF- $2 \alpha$ from the Day- 15 guinea-pig uterus was not inhibited by TMB- $8(150 \mu \mathrm{M})$. This finding indicates that a maintained high intracellular free $\mathrm{Ca}^{2+}$ concentration is not necessary for maintaining the high rate of PGF-2 $\alpha$ synthesis by and release from the Day-15 guinea-pig endometrium during the period of superfusion. Although raising the free intracellular $\mathrm{Ca}^{2+}$ concentration of the Day-7 guinea-pig uterus with A23187 stimulates PGF- $2 \alpha$ output, a prolonged increase in PGF- $2 \alpha$ production is not seen. Consequently, $\mathrm{Ca}^{2+}$ alone appears inadequate to produce a prolonged activation of PLA-2. Since the intrauterine administration of actinomycin $\mathrm{D}$ (a protein synthesis inhibitor) prevents luteal regression presumably by preventing the increase in uterine PGF- $2 \alpha$ output (Poyser, 1979), this previous finding and the present data suggest that oestradiol acting on a progesterone-primed uterus causes the synthesis of a protein (a 'lipostimulin') which causes prolonged stimulation of PLA-2 at a low free $\mathrm{Ca}^{2+}$ concentration and thus results in a continuous release of arachidonic acid for endometrial PGF- $2 \alpha$ synthesis. Whether such a protein exists and whether $\mathrm{Ca}^{2+}$ is involved initially in its action required further study.

W-7 prevented the increase in uterine PG output induced by $A 23187$, providing further evidence that calmodulin is involved in the mechanism by which raising the intracellular free $\mathrm{Ca}^{2+}$ con- 
centration stimulates uterine PG synthesis and release (Poyser, 1985). W-7 (150 $\mu \mathrm{M})$ did not inhibit the high basal output of PGF-2 $\alpha$ from the Day-15 uterus while being superfused over the tissue. However, there was a significant $(P<0.05) 50 \%$ drop $20-30$ min after stopping the W-7 treatment but whether this indicates that calmodulin is involved in the mechanism by which oestradiol and progesterone cause prolonged stimulation of uterine PGF- $2 \alpha$ production requires further investigation. In a previous study, trifluoperazine, another calmodulin antagonist, did not produce this 'late' inhibitory effect and, in fact, had no inhibitory effect on basal uterine PG output (Poyser, 1985). Indomethacin inhibits basal uterine PG output shortly after the start of being superfused over the tissue (Poyser, 1985), showing that neither TMB-8 nor W-7 are cyclo-oxygenase inhibitors.

TMB- 8 and W-7 both caused an initial increase in uterine PG output, a phenomenon previously reported for trifluoperazine and which may be due to the release of membrane-bound $\mathrm{Ca}^{2+}$ (Poyser, 1985). The increases were transient, except that TMB- 8 caused a prolonged stimulation of uterine PGE-2 output (Text-fig. 1). Another strange finding was that, following treatment with TMB-8 $(150 \mu \mathrm{M})$ or $\mathrm{W}-7(150 \mu \mathrm{M})$ in combination with $\mathrm{A} 23187$, there was a specific increase in uterine 6-keto-PGF-1 $\alpha$ output (Text-fig. 3). This was not due to the gradual increase in uterine tone, since the increase in uterine 6-keto-PGF- $1 \alpha$ output did not follow TMB-8 or W-7 treatment alone although the increase in tone still occurred. Obviously A23187 had a delayed effect which was presumably restricted to the myometrium, the major site of 6-keto-PGF-1 $\alpha$ synthesis in the guinea-pig uterus (Poyser, 1983b).

This study was supported by a grant from the S.E.R.C. The technical help of Miss Isa Ramsay and Miss Lorna Marshall is much appreciated. W-7 was supplied as a gift from BeechamWulfring, Gronau (Leine), West Germany, and authentic PGs were kindly supplied by the Upjohn Co., Kalamazoo, Michigan, U.S.A.

\section{References}

Dighe, K.K., Emslie, H.A., Henderson, L.K., Rutherford, F. \& Simon, L. (1975) The development of antisera to prostaglandins $B_{2}$ and $F_{2 \alpha}$ and their analysis using solid phase and double antibody radioimmunoassay methods. Br. J. Pharmac. 55, 503-514.

Downing, I. \& Poyser, N.L. (1983) Estimation of phospholipase $A_{2}$ activity in guinea-pig endometrium on Days 7 and 16 of the estrous cycle. Prostaglandins, Leuk. \& Med. 12, 107-117.

Hidaka, H., Asano, M., Iwadare, S., Mutsumoto, I., Totsuka, T. \& Aoki, N. (1978) A novel vascular relaxing agent $\mathrm{N}$-(6-aminohexyl)-5-chloro-1-naphthalenesulphonamide. J. Pharmac. exp. Therap. 207, 8-15.

Horton, E.W. \& Poyser, N.L. (1976) Uterine luteolytic hormone: a physiological role for prostaglandin $\mathbf{F}_{2 a}$. Physiol. Rev. 56, 595-651.

Leaver, H.A. \& Poyser, N.L. (1981) Distribution of arachidonic acid and other fatty acids in the lipids of guinea-pig uterus and plasma in relation to uterine prostaglandin synthesis. J. Reprod. Fert. 61, 325-333.

Lytton, F.D.C. \& Poyser, N.L. (1982) Concentration of PGF- $2 \alpha$ and PGE-2 in the uterine venous blood of rabbits during pseudopregnancy and pregnancy. $J$. Reprod. Fert. 64, 421-429.

Malagodi, M.H. \& Chiou, C.Y. (1974) Pharmacological evaluation of new $\mathrm{Ca}^{2+}$ antagonist, 8 -( $N, N$-diethylamino)-octyl-3,4,5-trimethyoxybenzoate hydrochlor- ide (TMB-8): studies in smooth muscle. Eur. $J$. Pharmac. 27, 25- 33.

Mitchell, S., Poyser, N.L. \& Wilson, N.H. (1977) Effect of $p$-bromophenacyl bromide, an inhibitor of phospholipase $A_{2}$, on arachidonic acid release and prostaglandin synthesis by the guinea-pig uterus. $\mathrm{Br}$. J. Pharmac. 59, 107-113.

Poyser, N.L. (1979) Effect of actinomycin D on uterine prostaglandin production and oestrous cycle length in guinea-pigs. J. Reprod. Fert. 56, 559-565.

Poyser, N.L. (1980) Development and use of radioimmunoassay for measuring 6-oxo-prostaglandin $\mathrm{F}_{10 .}$. In Prostaglandins, Prostacyclin and Thromboxane Measurement, pp. 44-55. Eds J. M. Boeynaems \& A. G. Herman. Martinus Nijhoff, The Hague.

Poyser, N.L. (1981) Prostaglandins in Reproduction. John Wiley \& Sons Ltd, Chichester.

Poyser, N.L. (1983a) Effect of treating ovariectomized guinea-pigs with estradiol and progesterone on basal and A23187-stimulated release of prostaglandins from the uterus superfused in vitro. Prostaglandins, Leuk. \& Med. 11, 345-360.

Poyser, N.L. (1983b) Differential stimulation of prostaglandin and thromboxane synthesizing capacities in the guinea-pig uterus and ovary. Prostaglandins, Leuk. \& Med. 10, 163-177. 
Poyser, N.L. (1984a) Effect of using calcium-free Krebs' solution on basal and A23187-stimulated prostaglandin output from the Day-15 guinea-pig uterus superfused in vitro. Prostaglandins, Leuk. \& Med.13, 259-269.

Poyser, N.L. (1984b) Prostaglandin production by the early pregnant guinea-pig uterus in relation to implantation and luteal maintenance, and the effect of oestradiol. J. Reprod. Fert. 72, 117-127.

Poyser, N.L. (1985) Effect of trifluoperazine, a calmodulin antagonist, on prostaglandin output from the guinea-pig uterus. J. Reprod. Fert. 73, 295-303.

Poyser, N.L. \& Brydon, L.J. (1983) Prostaglandin release from the guinea-pig uterus superfused in vitro. Effect of stage of estrous cycle, progesterone, estradiol, oxytocin and A23187. Prostaglandins, 25, 443-456.
Poyser, N.L. \& Horton, E.W. (1975) Plasma progesterone levels in guinea-pigs actively immunized against prostaglandin $\mathbf{F}_{2 a}$, hysterectomized or treated with intra-uterine indomethacin. $J$. Endocr. 67, 81-88.

Poyser, N.L. \& Scott, F.M. (1980) Prostaglandin and thromboxane production by the rat uterus and ovary in vitro during the oestrous cycle. J. Reprod. Fert. 60, 33-40.

Swan, C.G. \& Poyser, N.L. (1983) Prostaglandin synthesis by, and the effects of prostaglandins and prostaglandin analogues on, the vas deferens of the rabbit and rat in vitro. J. Reprod. Fert. 69, 91-99.

Received 28 January 1985 